\title{
ANTIFUNGAL ACTIVITY OF DIFFERENT NEEM LEAF EXTRACTS AND THE NIMONOL AGAINST SOME IMPORTANT HUMAN PATHOGENS
}

\author{
Mahmoud, D.A.*;Hassanein, N.M.; Youssef, K.A.; Abou Zeid, M.A.
}

Department of Microbiology, Faculty of science, Ain-Shams University, 11566, Abbassia, Cairo, Egypt.

Submitted: May 22, 2010; Returned to authors for corrections: August 23, 2010; Approved: January 13, 2011.

\begin{abstract}
This study was conducted to evaluate the effect of aqueous, ethanolic and ethyl acetate extracts from neem leaves on growth of some human pathogens (Aspergillus flavus, Aspergillus fumigatus, Aspergillus niger, Aspergillus terreus, Candida albicans and Microsporum gypseum) in vitro. Different concentrations (5, 10, 15 and 20\%) prepared from these extracts inhibited the growth of the test pathogens and the effect gradually increased with concentration. The $20 \%$ ethyl acetate extract gave the strongest inhibition compared with the activity obtained by the same concentration of the other extracts. High Performance Liquid Chromatography (HPLC) analysis of ethyl acetate extract showed the presence of a main component (nimonol) which was purified and chemically confirmed by Nuclear Magnetic Resonance (NMR) spectroscopic analysis. The 20\% ethyl acetate extract lost a part of its antifungal effect after pooling out the nimonol and this loss in activity was variable on test pathogens. The purified nimonol as a separate compound did not show any antifungal activity when assayed against all the six fungal pathogens.
\end{abstract}

Key words: Azadirachta indica, Aqueous and organic extracts, HPLC, Fungal inhibitory effect

\section{INTRODUCTION}

Neem (Azadirachta indica) tree has attracted worldwide prominence owing to its wide range of medicinal properties. Neem leaf and its constituents have been demonstrated to exhibit immunomodulatory, anti-inflammatory, antihyperglycaemic, antiulcer, antimalarial, antifungal, antibacterial, antioxidant, antimutagenic and anticarcinogenic properties (26).

Leaf and seed extracts of $A$. indica were tested for antidermatophytic activity and found effective against some dermatophytes such as Trichophyton rubrum, T. violaceaum, Microsporum nanum and Epidermophyton floccosum by the tube dilution technique (16) and on C. albicans (17).

The minimum inhibitory concentration (MIC) and minimum fungicidal concentration (MFC) for extracts from leaves and seeds of neem were evaluated (17) against various dermatophytes. The authors found that changes in the growth curve of the treated dermatophytes were statistically significant with reference to the untreated fungi. The MIC of extracts from neem leaves and seeds were 31 and $15 \mu \mathrm{g} / \mathrm{ml}$, respectively and which was sufficient to destroy Trichophyton rubrum, $T$.

\footnotetext{
*Corresponding Author. Mailing address: Department of Microbiology, Faculty of Science, University of Ain Shams, Elkhalifa Elmamoun street, 11566,Abbassia, Cairo,Egypt.; Tel.: +20103887237, Fax: +20226842123.; E-mail: drdaliaali@ yahoo.com
} 
mentagrophytes and Microsporum nanum.

Neem seed oil is used to treat certain chronic skin diseases, ulcers, different types of metritis, leprosy, gum and dental troubles and the seed oil is said to be non-mutagenic. However, neem seed oil is toxigenic when given orally and further studies might throw light on the systemic toxicity of the solvent extracts of the neem seed (3).

Neem elaborates a vast array of biologically active compounds that are chemically diverse and structurally variable with more than 140 compounds isolated from different parts of the tree (26). Quercetin and B-sitosterol, were the first polyphenolic flavonoids purified from neem fresh leaves and were known to have antibacterial and antifungal properties (9). The same authors purified the active fractions of neem organic extracts using HPLC and found that their content of major compounds such as 6-deacetylnimbin, azadiradione, nimbin, salannin and epoxy-azadiradione were with appreciable active when bioassayed on many pathogenic fungi (9). Trish et al. (28) determined the chemopreventive potential of $A$. indica leaf extract in murine carcinogenesis model system of 7-week-old Swiss albino mice and reported that tumor incidence was reduced by doses of neem leaf extract. The results revealed that the Indian neem tree contained at least 35 biologically active principles.

The present investigation aimed to (1) compare the antifungal activity of aqueous and organic (ethanole and ethyl acetate) extracts from neem leaves against six important human pathogens (A. flavus, A. fumigatus, A. niger, A. terreus, C. albicans and M. gypseum); (2) to analyze the contents of the most active extract using HPLC and determine the antifungal activity of the main component against the same test pathogens.

\section{MATERIALS AND METHODS}

\section{Neem leaves}

Neem leaves (Azadirachta indica A. Juss) were collected from 10-12 years old trees from Kalyoub Administry of
Agriculture, Kalyoub city, Egypt.

\section{Pathogenic fungi}

The test fungal pathogens (Aspergillus flavus, A. fumigatus, A. niger, A. terreus, Candida albicans and Microsporum gypseum) were obtained from the Microbiological Resource Center (MIRCEN), Faculty of Agriculture, Ain Shams University, Cairo, Egypt.

\section{Preparation of different leaf extracts}

The preparation of aqueous neem leaf extract was carried out according to the method described by (23). Whereas organic extracts were prepared following the method of (19).

\section{Antifungal activity of different extracts of neem leaves}

The antifungal effect of aqueous and organic extracts of neem leaves was assessed by measuring radial growth of the test pathogens following the technique described by (5).

\section{HPLC analyses and chromatographic purification of nimonol}

Analysis of different components present in the mother organic extract in ethyl acetate obtained from neem leaves was performed according to the method (8). The organic extract was fractionated by HPLC apparatus (Perkin-Elmer, Norwalk, CT, USA) consisted of the following: A 410 LC pump equipped with a LC 90 UV spectrophotometric detector and a LCI 100 integrator at $230 \mathrm{~nm}$ using acherey-nagel $100 \mathrm{C}-18$ columns (20 mm x $25 \mathrm{~cm}, 215 \mathrm{~nm})$. The mobile phase included methanol (Carlo Erba, Milan, Italy) and Ultra pure water purified in a Milli-Q system (Millipore, Bedford, MA, USA). The chromatographic run which lasted for $2 \mathrm{~h}$ was carried out for samples $(20 \mu \mathrm{l}$ for each) containing $3 \mathrm{mg}$ EtoAc extract dissolved in $1 \mathrm{ml}$ methanol at a flow rate of $20 \mathrm{ml} / \mathrm{min}$ through a stepwise gradient solvents in the following order: methanol : water (70:30) for 40 minutes; methanol : water (80: 20) for another 40 minutes and finally methanol : water (90: 10\%) for 20 min before a final column wash after run completion with 
methanol in order to remove the non-polar components. Three successive injections were carried out for the neem leaf organic extract and for pure authentic samples of the following: azadirachtins (Sigma-Aldrich (St. Louis, MO, USA). The main component contained in peak no. 7 was separated at $63 \mathrm{~min}$. by HPLC for spectroscopic analyses $\left({ }^{1} \mathrm{H}\right.$ - and $\left.{ }^{13} \mathrm{C}-\mathrm{NMR}\right)$.

\section{Spectral analysis of nimonol}

A solution of nimonol $(2.5 \mathrm{mg})$ in pyridine $(0.25 \mathrm{ml})$ and $\mathrm{Ac}_{2} \mathrm{O}(0.25 \mathrm{ml})$ was kept at room temperature for 24 hours. A chromatographic purification using analytical silica gel chromatographic plates (Kieselgel 60, $\mathrm{F}_{254}$, Merck, Germany) and elution was carried out using $10 \%$ EtoAc in n-hexane.

\section{NMR spectral analysis}

${ }^{1} \mathrm{H}-\mathrm{NMR}$ and ${ }^{13} \mathrm{C}-\mathrm{NMR}$ spectral analyses were recorded in CD3OD at 200 and $400 \mathrm{MHz}$ on Bruker Spectrometeres using the same solvent as internal standard. Chemical shifts are given at $\delta$ value while coupling constants $(J)$ are in $\mathrm{Hz}$, carbon multiplicities were determined by distortion enhancement by polarization transfer "DEPT".

\section{Antifungal activity of nimonol}

The purified nimonol was tested for antifungal activity against all tested pathogens in comparison to the following: mother organic extract in ethyl acetate $20 \%$ (A), (A) free from nimonol (B) as described by (5).

\section{Statistical analysis}

The data were analyzed by using a completely randomized factorial design (21). Significant differences between treatment means were determined using Costal Program. Biological results were analyzed by One Way ANOVA.

\section{RESULTS}

\section{Activity of different neem leaf extracts against some human pathogenic fungi}

In general, two of the tested Aspergelli (A. flavus and $A$. niger) were highly sensitive during assays whereas $C$. albicans and M. gypseum were the weakest. The $20 \%$ concentration of ethyl acetate extract gave the highest inhibition activity against all test pathogens in all used concentrations compared with the same concentrations from other extracts.

\section{Activity of aqueous extract}

The $5 \%$ aqueous leaf extract of neem caused an inhibition in growth of the six test fungal pathogens. The highest one (35.22\%) was recorded on A. niger while the lowest $(4.00 \%)$, was on C. albicans (fig.1-A). A concentration of $10 \%$ moderately inhibited the growth of all test fungi with the highest value $(49.55 \%)$ recorded on $A$. niger and the lowest (11.53\%) on C. albicans (fig.1-B). An inhibition by $86.22 \%$ was recorded on the growth of A. niger compared with $38.44 \%$ in the growth of $M$. gypseum (fig.1-C), when the neem leaf aqueous extraxt was assayed at a concentration of $15 \%$. These ratios of inhibition jumped to $100 \%$ and $53.66 \%$ in the growth of $A$. niger and M. gypseum (fig.1-D) during the assay with the $20 \%$ concentration.

\section{Activity of organic extracts}

In assays using extracts in ethanol, the 5\% concentration gave $44.22 \%$ inhibition of $A$. flavus and $20.30 \%$ of C. albicans (fig.1-A) whereas the $10 \%$ scored higher values recorded for $A$. flavus (47.44\%) and C. albicans (26.92\%) (fig.1-B). By increasing the extract concentration, the $15 \%$ (fig.1-C) and $20 \%$ (fig.1-D) highly suppressed the mycelia growth of all tested pathogenic fungi.

When the antifungal activity was measured for all the six fungal pathogens using the extracts in ethyl acetate, values of inhibition in their growth significantly differed. The first concentration (5\%) affected A. flavus by $54.33 \%$ and $C$. albicans by $9.84 \%$ (fig.1-A). Fig.1-B is showing a marked growth inhibition in growth of test fungi and the concentration of $15 \%$ characteristically inhibited both A. flavus $(91.11 \%)$ and A. niger (88.50\%), whereas M. gypseum was the least affected 
$(64.88 \%)$ (fig.1-C). A maximum inhibition in growth which reached $100 \%$ was recorded for the first time on two of the pathogenic fungi (A. flavus and A. niger), when a concentration of $20 \%$ from the same organic extract was used (fig.1-D).

(A)

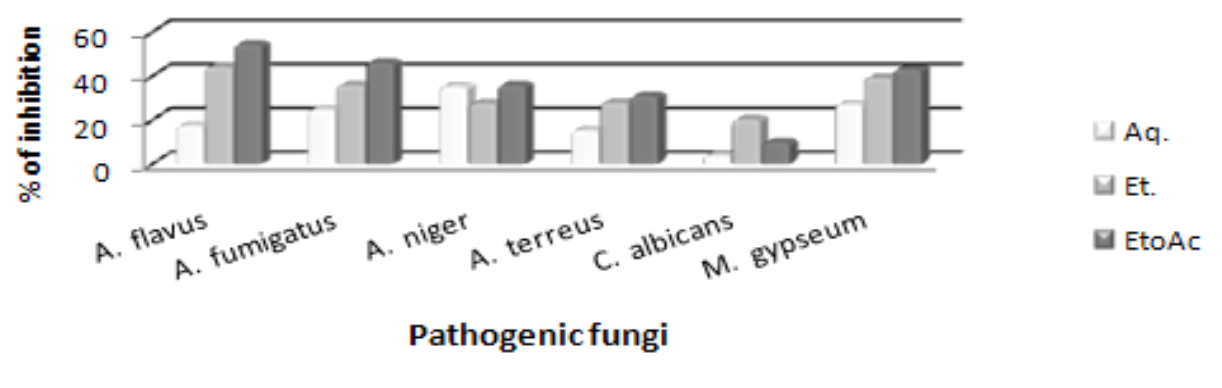

(B)

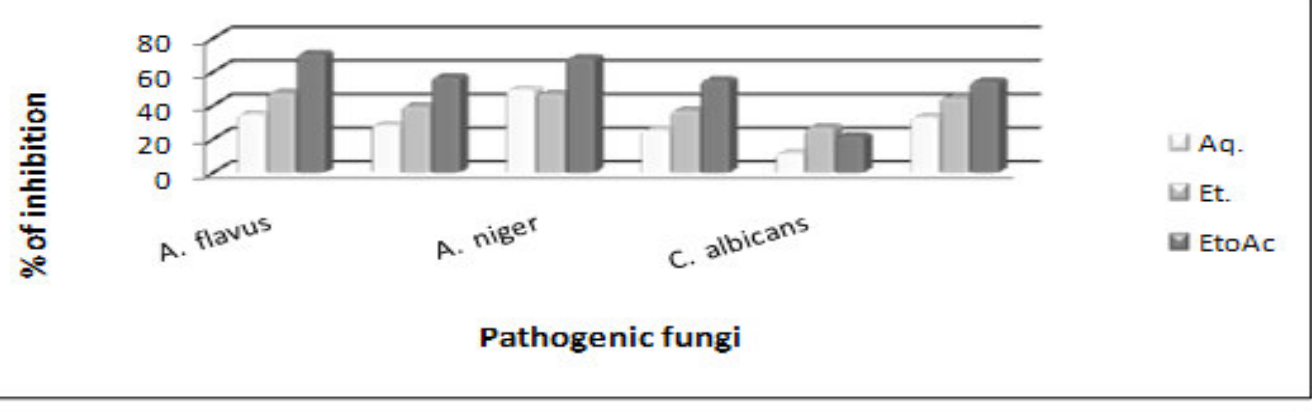

(C)

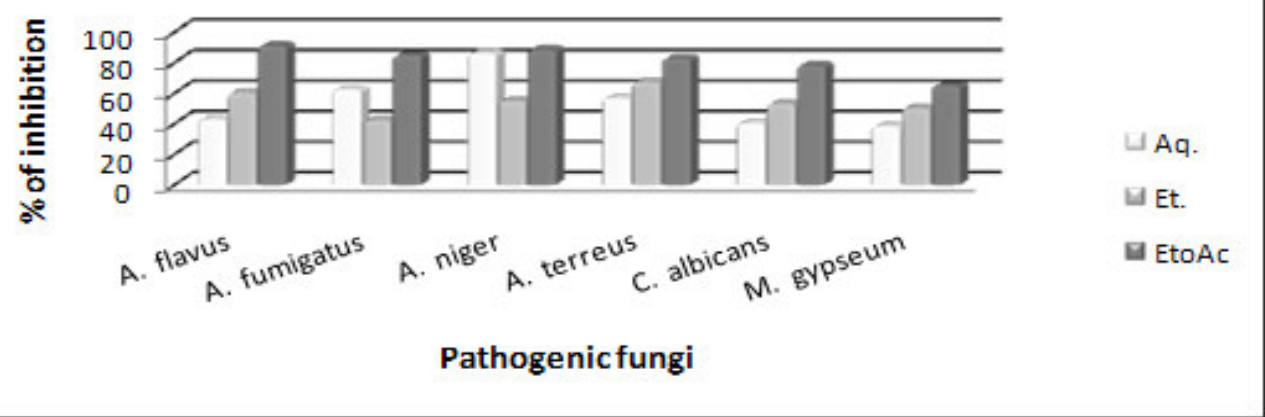

(D)

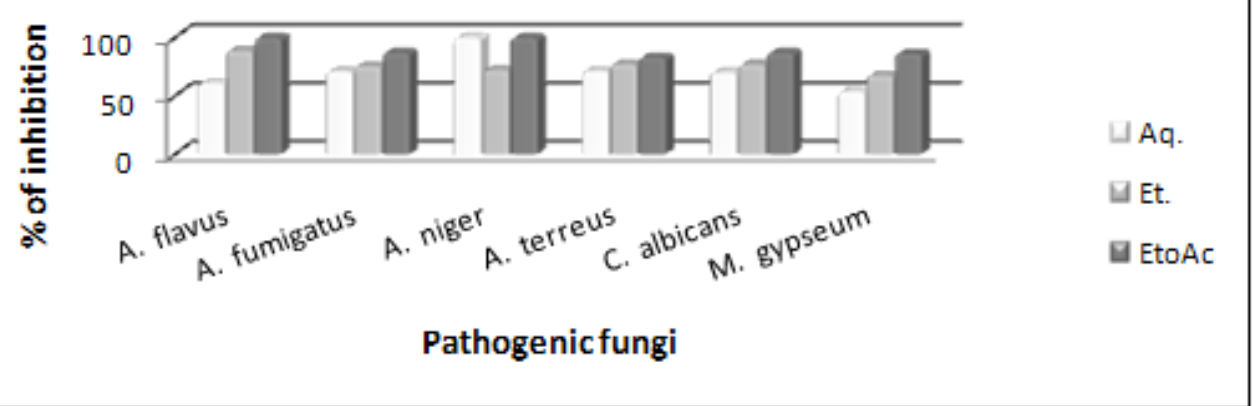

Figure 1. (A): Effect of different concentrations (5\%) of aqueous (Aq.), ethanolic (Et.) and ethylacetate (EtoAc) leaf extracts of neem on growth of pathogenic fungi on solid media. (B): Effect of different concentrations (10\%) of aqueous (Aq.), ethanolic (Et.) and ethylacetate (EtoAc) leaf extracts of neem on growth of pathogenic fungi on solid media. (C): Effect of different concentrations (15\%) of aqueous (Aq.), ethanolic (Et.) and ethylacetate (EtoAc) leaf extracts of neem on growth of pathogenic fungi on solid media. (D): Effect of different concentrations (20\%) of aqueous (Aq.), ethanolic (Et.) and ethylacetate (EtoAc) leaf extracts of neem on growth of pathogenic fungi on solid media. 
HPLC analyses and chromatographic separation of nimonol

The HPLC diagram of the highly active organic extract (A) showed ten well defined chromatographic peaks (Table 1 and Figure 3). These peaks were eluted at different retention time $\left(\mathrm{r}_{t}\right)$. The first peak was eluted after $9 \mathrm{~min}$. and contained three Azadirachtins (A, B, and C) at ratios of 7\%, 5\% and $8 \%$, respectively. The third peak was evident at $r_{t}$ of $22 \mathrm{~min}$ and contained the azadirachtins $\mathrm{A}, \mathrm{B}, \mathrm{D}, \mathrm{H}$ and $\mathrm{I}$ at ratios of $11 \%$, $10 \%, 4 \%, 9 \%$, and $7 \%$, respectively. The $4^{\text {th }}$ Peak was eluted after $34 \mathrm{~min}$ and was identified as 6 de-acetyl nimbin of $39 \%$ purity. The peaks no. 2 and 5 (eluted at $\mathrm{r}_{t} 16$ and $39 \mathrm{~min}$, respectively) yielded very small amounts of non-pure material and were not enough for accurate identification. Peak no. 6 was eluted at $54 \mathrm{~min}$ and contained mainly the azadiradione (51\%) whereas at $63 \mathrm{~min}$, peak no. 7 was eluted and contained the nimonol with the highest purity level ( $82 \%)$, followed by peak no. 8 at 68.6 min which contained the epoxyazadiradione as a major constituent (43\%). The last two peaks (9 and 10) were eluted after 76 and $90 \mathrm{~min}$, respectively and contained also small amounts of non-pure materials especially the last one which seems containing at least three components (Table 1).

Table 1. HPLC pattern of neem leaf ethylacetate (EtoAc) extract.

\begin{tabular}{cccc}
\hline Band no. & $\mathbf{r}_{\boldsymbol{t}}$ (min.) & Total peak area etected (\%) & ID \\
\hline Band 1 & 9 & $69.8 \%$ & Azadirachtins: A (7\%), B (5\%), C (8\%) \\
Band 2* & 16 & $21.6 \%$ & Not identified \\
Band 3 & 22 & $56.4 \%$ & Azadirachtins: A (11\%), B (10\%), D (4\%),H (9\%), I (7\%) \\
Band 4 & 34 & $32.7 \%$ & 6 De-acetyl nimbin (39\%) \\
Band 5* & 39 & $40.0 \%$ & Not identified \\
Band 6 & 54 & $66.0 \%$ & Azadiradione $(51 \%)$ \\
Band 7 & 63 & $74.0 \%$ & Nimonol (82\%) \\
Band 8 & 68.6 & $30.0 \%$ & Epoxyazadiradione $(43 \%)$ \\
Band 9* & 76 & $32.0 \%$ & Not identified \\
Band 10* & 90 & $25.0 \%$ & Not identified \\
\hline
\end{tabular}

Peaks analyzed by preparative HPLC using the same solvent system and found to be complex mixtures; quantities of pure material collected following their purification were very small to be considered for further investigation.

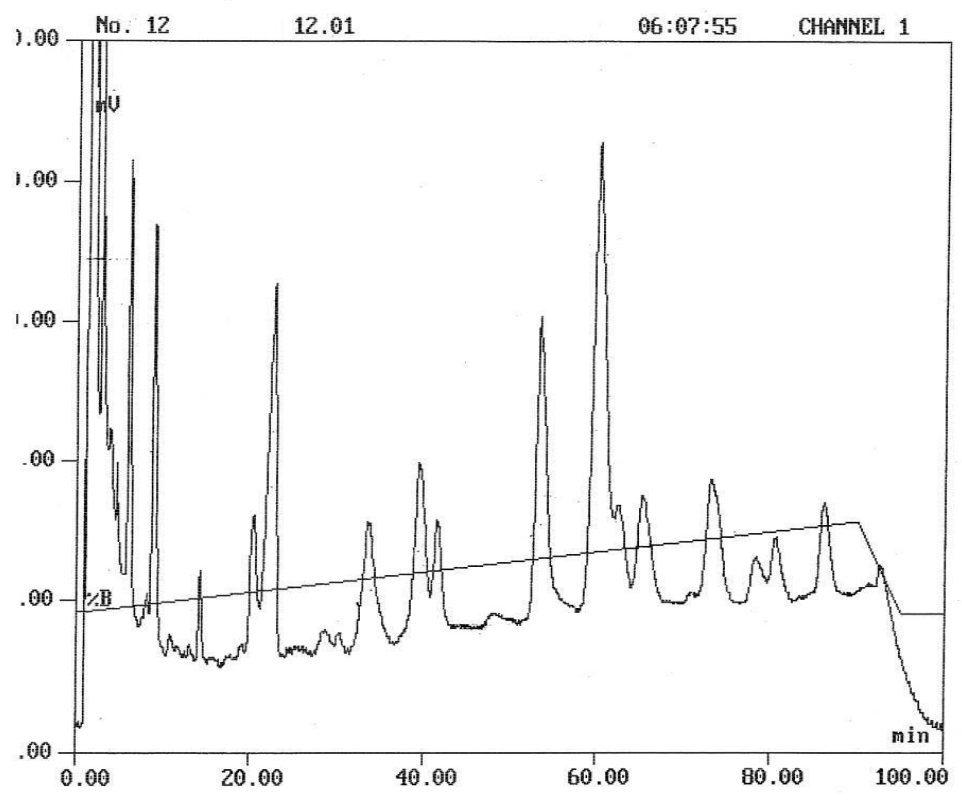

Figure 3. High performance liquid chromatographic pattern of neem leaf ethylacetate extract. 


\section{Purification and spectral identification of nimonol}

The used HPLC linear gradient solvent which consisted of a mixture from methanol and water permitted the separation of the pure compound contained in peak no. 7 and which was subjected to NMR spectral analysis for the complete identification.

The ${ }^{1} \mathrm{H}$-NMR signals of nimonol were at $\delta 7.38 \mathrm{~m} ; 7.26 \mathrm{~m}$; $6.29 m$ ( $\beta$-substituted furan); $7.12 d, J=10.06 \mathrm{~Hz} ; 5.90 d, J=$ $10.06 \mathrm{~Hz}(-\mathrm{CH}=\mathrm{CH}-\mathrm{CO}-) ; 5.42 d d, J=1.82,2.84 \mathrm{~Hz}(\mathrm{C}=\mathrm{CH}-$ $\left.\mathrm{CH}_{2}\right), 2.05\left(\mathrm{CH}_{3} \mathrm{CO}\right)$. The ${ }^{1} \mathrm{HNMR}$ spectrum showed also three methane protons at $\delta 2.21 d ; J=11.65 \mathrm{~Hz}(-\mathrm{CH}-) ; 4.38 d d, J=$ $11.65 \mathrm{~Hz}$ and $2.37(-\mathrm{CHOH})$ and $5.35 d, J=2.37 \mathrm{~Hz}$ (-CHOAc-).
Coupling of the last three methane protons was recorded in correlated spectroscopy (COSY) where the proton at $\delta 2.21$ had cross peaks with that at $\delta 4.38$ whereas the proton at $\delta 4.38$ had cross peaks with those at $\delta 2.21, \delta 5.31$ in addition to the proton at $\delta 5.36$ with that at $\delta 4.38$. The COSY spectrum also showed the presence of the characteristic group $-\mathrm{CH}-\mathrm{CHOH}-$ CHOAc on a cyclohexane ring system.

The ${ }^{13} \mathrm{C}$-NMR spectrum of nimonol revealed the presence of an important signal which corresponds to the olefinic bond between $\mathrm{C}-14$ at $158.51 \mathrm{ppm}$ and $\mathrm{C}-15$ at $119.54 \mathrm{ppm}$ and which are characteristic for this class of compounds. The complete ${ }^{1} \mathrm{H}$ ${ }^{13} \mathrm{C}$-NMR spectral data are represented in (Table 2).

Table 2. ${ }^{1} \mathrm{H}$ and ${ }^{13} \mathrm{C}-\mathrm{NMR}$ spectral data* of the purified nimonol

\begin{tabular}{|c|c|c|c|c|c|}
\hline $\begin{array}{c}\text { Detected } \\
\text { Protons } \\
\end{array}$ & $\delta$ & signal & $\begin{array}{c}J \\
(\mathbf{H z}) \\
\end{array}$ & Detected carbons & $\delta$ \\
\hline H-1 & 7.12 & $d$ & 10.06 & C-1 & 157.63 \\
\hline H-2 & 5.9 & $d$ & 10.06 & C-2 & 126.33 \\
\hline H-5 & 2.21 & $d$ & 11.68 & $\mathrm{C}-3$ & 204.98 \\
\hline H-6 & 4.38 & $d d$ & $1.62,2.37$ & C-4 & 40.08 \\
\hline $\mathrm{H}-7$ & 5.36 & $d$ & 2.37 & $C-5$ & 50.36 \\
\hline H-15 & 5.42 & $d d$ & $1.82,2.84$ & $C-6$ & 68.42 \\
\hline $\mathrm{H}-17$ & 2.83 & $d d$ & & $\mathrm{C}-7$ & 78.83 \\
\hline $\mathrm{H}-21$ & 7.26 & $M$ & & C-8 & 44.46 \\
\hline $\mathrm{H}-22$ & 6.29 & $m$ & & C-9 & 38.09 \\
\hline $\mathrm{H}-23$ & 7.39 & $m$ & & C-10 & 42.59 \\
\hline Oac & 2.05 & & & C-11 & 16.52 \\
\hline $\mathrm{OH}$ & n.d. & & & C-12 & 32.77 \\
\hline \multirow[t]{3}{*}{ C-methyls } & 0.82 & & & C-13 & 46.66 \\
\hline & & & & OAc & 119.55 \\
\hline & & & & C-methyls & 33.65 \\
\hline
\end{tabular}

Chemical shifts are recorded in $(\delta)$ values $(\mathrm{ppm})$ in $\mathrm{CDcl}_{3}$ and $\mathrm{CD}_{3} \mathrm{OD}$, respectively.

\section{Antifungal activity of nimonol}

Data represented in Fig. 2 shows the antifungal activity of the purified nimonol when tested separately against the six test human pathogens. Results revealed that the pure nimonol alone as a compound has no inhibitory effect on the growth of all test fungi when assayed at concentration of $20 \%$. Values recorded indicates 2-3 times-higher inhibition values for the extract (A) over that of (B) against the tested pathogens. For extract (B), it was found that the inhibition percentages of the test pathogens were lowered after pooling out nimonol (peak no. 7) from the mother extract (A) at all concentrations. Values of inhibition for the extract (A) when assayed at a concentration of $20 \%$ showed the highest inhibition percentages against A. flavus (55.28\%) and M. gypseum (42.12\%). 


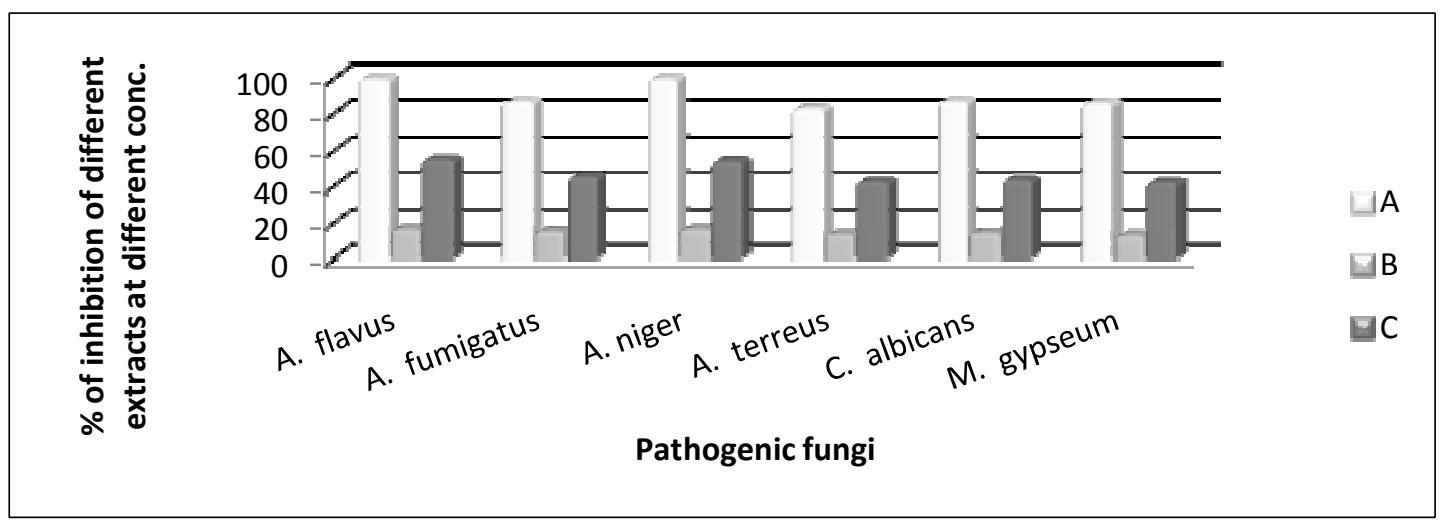

Figure 2. Percentage of inhibition of different ethylacetate extracts (Aand B) and pure nimonol on the growth of pathogenic fungi.

\section{DISCUSSION}

Results obtained during assay with aqueous and organic extracts from neem leaves showed their inhibitory effect at all used concentrations against the sex pathogenic fungi. These human pathogens included four Aspergillus species (A. niger, A. flavus, A. terrues and A. fumigatus) which are known to cause aspergilloses, in addition to Microsporum gypseum (a dermatophyte) and Candida albicans, the causal agent of dermatophytosis and candidiases. All concentrations of the aqueous extract effectively suppressed the mycelial growth of these fungi and this effect was found to increase with concentration where a maximum activity was reached using the last one (20\%). These results are in agreement with Dube and Tripathi (6) who showed that the aqueous extracts of $A$. indica obtained from bark and leaf, inhibited both spore germination and mycelial growth of Epidermophyton floccosum, Microsporum canis and Trichophyton mentagrophytes. They also found that this antifungal toxic effect was also retained in organic extracts using ethanol. The $20 \%$ aqueous neem leaf extract had a toxic effect on 19 out of 22 tested moulds including Aspergillus flavus (10).

Also, different types of extracts from neem leaves were found to have inhibitory effect on Candida albicans (15).

The complete inhibition (100\%) in the growth of A. niger obtained in assay with $20 \%$ concentration of aqueous leaf extract of neem agrees with the results of Bohra and Purohit (2) who mentioned that the aqueous extracts of $A$. indica gave the highest inhibition of A. flavus growth.

The inhibition in growth of the six test fungi by organic extracts were higher than those recorded by the aqueous ones. It was found that all concentrations of organic extracts (in ethanol and ethyl acetate) effectively suppressed the mycelial growth and the recorded values were increasing gradually with concentration and reaching the highest ones with $20 \%$. This concentration gave $88.77 \%$ on A. flavus growth and $100 \%$ in the growth of A. flavus and A. niger.

Khan et al. (12) reported that some leaf extracts including those from neem had a characteristic effect on dermatophytes especially for low polar extracts over the high polar ones. The authors suggested that one possible explanation for this is the flavonoid quercetin contained in the extracts. Shivpuri et al. (24) noticed that the extracts in ethanol of $A$. indica had fungitoxic properties against five pathogenic fungi when tested under laboratory conditions at concentrations ranging between 500 and $1000 \mu \mathrm{g} \mathrm{ml}^{-1}$. The results obtained during assay with organic extracts were also in accordance with those recorded by Verma et al. (30) who found that a purified fraction (ethyl acetate : chloroform, 3:1) of extracts in methanol from neem seed coat showed strong antifungal activity against $A$. niger and Curvularia lunata with MIC of $250 \mathrm{ppm}$. They found also that the extracts in petroleum ether from the neem leaves were 
highly active at a lower MIC (100 ppm) against the same pathogens. In recent study, Kishore et al. (13) reported that ethanolic leaf extracts of A.indica inhibited the conidial germination of Phaeoisariopsis personata by $>90 \%$ to control late leaf spot of groundnut.

Upasana et al. (29) found that neem seed extract in methanol was effective against Aspergillus niger, Fusarium oxysporum and Trichoderma resii and that both dried and fresh organic extracts from leaves were effective only against Trichoderma resii.

Leaf extracts of neem were found to have a potent antidermatophytic activity against Trichophyton rubrum, $T$. violaceaum, Microsporum nanum and Epidrmophyton floccosum (16). The same extracts were found to have interesting inhibitory action on a wider spectrum of microorganisms, including C. albicans, C. tropicalis, Neisseria gonorrhea, multi-drug resistant Staphylococcus aureus, urinary tract E. coli, Herpes simplex-2 and HIV with safety of the used formulations and acceptability (26). The kill kinetics of $A$. indica was determined by Okemo et al. (18) on different pathogenic microorganisms including Staphylococcus aureus, Escherichia coli, Pseudomonas aeruginosa and Candida albicans. They concluded that the killing ability of $A$. indica extracts is time and concentration dependent and cell wall related.

Singh et al. (25) owed the fungicidal and bactericidal properties of extracts from neem leaves either in vitro or in vivo trials to the presence of several antimicrobial active ingredients in leaves of neem tree such as desactylimbin, quercetin and sitosterol. Whereas other researchers explained this activity by the presence of active ingredients like triterpenes or the limonoids such as meliantriol, azadirachtin, desactylimpin, quercetin, sitosterol, nimbin, nimbinin, nimbidin, nimbosterol and margisine (1) and/or to different bitter substances such as alkaloids, phenols, resins, glycocides, terpenes and gums (7, 11). Lyer and Williamson (14) attributed antifungal properties of neem extracts to the inhibition in protease activity of dermatophytes induced by the neem organic extract.

The HPLC analysis of the most active organic extract (in ethyl acetate) showed 4 peaks containing mainly the triterpenoids, among these are the famous group of Azadirachtins A, B, C, D, H, and I which don't possess any antifungal activity as proved by Govindachari et al. (8). A similar analytical method was applied by Sharma et al. (22) who purified three major constituents with only nematicidal activity from the neem seed kernels on reversed phase medium-pressure liquid chromatography and allowed to separate the main component in a pure form which was identified later by NMR spectroscopic techniques as nimonol. ${ }^{1} \mathrm{H}-\mathrm{NMR}$ and ${ }^{13} \mathrm{C}-\mathrm{NMR}$ showed characteristic signals of $\beta$ substituted furan and chemical shifts of an olefinic bond between n C-14 and C-15 which confirm the chemical structure of nimonol. The COSY spectrum also showed the presence of the characteristic group (-CH-CHOH-CHOAc) on a cyclo hexane ring system. Nimonol is a naturally occurring limonoid (tetranortriterpinoid) with $\beta$-methyl group at C-13 (27).

It was noticed that a loss (40-50\%) occurs in the antifungal activity for the four used concentrations of the organic extract (in ethyl acetate) when the nimonol was pooled even if this compound proved to be inactive against the test fungi when separately assayed at the highest concentration (20\%). This reflects a possible potent synergism for the different constituents present in this organic extract which is together responsible for the characteristic antifungal activity recorded during this study. This conclusion was illustrated in a previous results by Govindachari et al. (9) who showed that a mixture of fractions eluted from the HPLC was more effective when assayed for antifungal activity than the purified constituents. The authors attributed the lowering in antifungal activity to an important fact that the triterpenoids when purified, loose effect whereas in combination, an additive synergism occurs between them and give the excellent activity recorded for the extract. 
The inhibition in the growth of dermatophytes was explained by changes in hydrophobicity of candidal cells during assays in yeast adhesion to hydrocarbons (20). This anti-adhesive mechanism was confirmed later by De Rezende Ramos et al. (4) who established the effect of neem extracts on cell surface hydrophobicity and biofilm formation, which affect the colonization by $C$. albicans.

In conclusion, the mixture of fractions eluted by HPLC was more effective than the pure nimonol, the low antifungal activity even at the highest concentration (20\%) may be explained by a fact that these triterpenoids, in combination exhibit an additive effect which produce the excellent antifungal activity recorded in this study for extracts from neem leaves.

\section{ACKNOWLEDGMENT}

The authors wish to thank Center of Statistical Analyses. Department of Mathematics, Faculty of Scince, El-Monoufya University for technical support during experiments. The authors acknowledge the assistance of Dr. Anna Andolfi (DISPA, Italy) for support during the identification of nimonol.

\section{REFERENCES}

1. Bhatnagar, D. and McCormick, S.P. (1988) : The inhibitory effect of neem (Azadirachta indica) leaf extracts on aflatoxin synthesis in Aspergillus parasiticus. Journal of the American Oil Chemists' Society, 65(7): 1166-1168.

2. Bohra, N.K.; Purohit, D.K. (2002). Effect of some aqueous plant extracts on toxigenic strain of Aspergillus flavus. Advances in Plant Sciences, 15 (1), 103-106.

3. Charmaine Lloyd, A.C.; Menon, T.; Umamaheshwari, K. (2005). Anticandidal activity of Azadirachta indica. Research Paper, 37(6), 386389.

4. De Resende Ramos, A.; Ludke Falcao, L.; Salviano Barbosa, G.; Helena Marcellino, L.; Silvano Gander, E. (2007). Neem (Azadirachta indica A. Juss) components: candidates for control of Crinipellis perniciosa and Phytophthora spp. Microbiol. Res., 162(3), 238-243.

5. Dixit, S.N.; Tripathi, S.C.; Upadhyay, R.R. (1976). The antifungal substances of rose flowers (Rosa indica). Economic Botany, 30, 344 371 .

6. Dube, S.; Tripathi, S. (1987). Toxicity of some plants against dermatophytes. National Academy of Sciences, India, Science Letters, $10(2), 45-48$.

7. Dubey, R.C.; Dwivedi, R.S. (1991). Fungitoxic properties of some plant extracts against vegetative growth and sclerotial viability of Macrophomina phaseolina. Indian phytopathology, 44 : 411-413.

8. Govindachari, T.R.; Gobalakrishnan, G.; Suresh, G. (1996). Isolation of various Azadirachtins from neem oil by preparative high performance liquid chromatography. J. Liq. Chromatogr. \& Rel. Technol.,19, 17291733.

9. Govindachari, T.R.; Suresh, G.; Gopalakrishnan, G.; Banumathy, B.; Masilamani, S. (1998). Identification of antifungal compounds from the seed oil of Azadirachta indica. Phytoparasitica, 26 (2), 1-8.

10. Grewal, P.S.; Grewal, S.K. (1991). Selective fungicidal properties of some plant extracts to mushroom weed moulds. Phytopathol. Mediterr., 27(2), 112-114.

11. Joshi, P.C.; Prakash, O.M.; Prakash, O.; Tauro, P.; Narwal, S.S. (1992). Allelopathic effects of litter extract of some tree species on germination seedling growth of agricultural crops. Proceedings First National Symposium. Allelopathy in agroecosystems (Agriculture \& foresty), February 12-14, 1992 held at CCS Haryana Agricultural University, Hisar 125. 004 , India. 127-128.

12. Khan, M.; Wassilew, S.W.; Schmutterer, H.; Ascher, K.R. (1987). in Natural Pesticides from the Neem Tree and Other Tropical Plants (eds Schmutterer, H. and Asher, K.R.), GTZ, Eschborn, Germany, 460-466.

13. Kishore, G.K.; Pande, S.; Rao, J.N. (2001). Control of late leaf spot of groundnut (Arachis hypogaea) by extracts from non-host plant species. Plant Pathology Journal, 17(5), 264-270.

14. Lyer, S.R.; Williamson, D. (1991). Efficacy of some plant extracts to inhibit the protease activity of Trichophyton spesies Geobios Tadhpur, 8(1), 3-6.

15. Matinuddin, K.; Zubairy, H.N.; Khan, M. (1998). Mycoss. Partl : antimycotic effect of Azadirachta indica on candida albicans . Hamdard Medicus, 41(4), 33-34.

16. Natarajan, V.; Pushkala, S.; Karuppiah, V.P.; Prasad, P.V. (2002). Antidermatophytic activity of Azardirachta indica (neem) by invitro study. Med Chem Anticancer Agents, 5(2),149-6.

17. Natarajan, V.; Venugopal, P.V.; Menon, T. (2003). Effect of Azadirachta indica (neem) on the growth pattern of dermatophytes. Indian Journal of Medical Microbiology, 21(2), 98-101.

18. Okemo, P.O.; Mwatha, W.E.; Chabrab, S.C.; Fabryc, W. (2001). The kill kinetics of Azadirachta indica A. juss. (Meliacae) extracts on Staphylococcus aureus, Escherichia coli, Pseudomonas aeruginosa and Candida albicans. African Journal of Science and Technology (AJST) 
Science and Engineering Series, 2(2), 113-118.

19. Pankajalakshmi, V.; Taralakshimi, V. (1994). Antidermatophytic activity of neem Azadirachta indica leaves in vitro. Indian J. of Pharmacology, 26: 141-143.

20. Polaquini, S.R.; Svidziniski, T.I.; Kemmelmeier, C.; Gasparetto, A. (2006). Effect of aqueous extract from neem (Azadirachta indica A. Juss) on hydrophobicity, biofilm formation and adhesion in composite resin by Candida albicans. Arch. Oral Biol., 51(6), 482-490.

21. SAS (1988). SAS User's Guide: Statistics. SAS Institute. Cary, N.C.

22. Sharma, V.; Walia, S.; Kumar, J.; Nair, M.G.; Parmar, B.S. (2003). An efficient method for the purification and characterization of nematicidal azadirachtins A, B, and H, using MPLC and ESIMS. J Agric Food Chem., 51(14), 3966-72.

23. Shetty, S.A.; Prakash, H.S.; Shetty, H.S. (1989). Efficacy of certain plant extracts against seed-born infection of Triconiella padwickii in paddy (Oryza sativa). Canadian J. of Botany, 67(7), 1956-1958.

24. Shivpuri, A.; Sharma, O.P.; Jhamaria, S.L. (1997). Fungitoxic properties of plant extracts against pathogenic fungi. Journal of Mycology and Plant Pathology, 27(1), 29-31.
25. Singh, U.P.; Singh, H.B.; Singh, R.B. (1980). The fungicidal effect of neem (Azadirachta indica) extracts on some soil borne pathogens, Mycologia, 7 : 1077-1093.

26. Subapriya, R.; Nagini, S. (2005). Medicinal properties of neem leaves: a review. Curr. Med. Chem. Anticancer Agents,5 (2),149-160.

27. Suresh, G.; Narasimhan, N.S.; Masilamani, S.; Partho, P.D; Gopalakrishnan, G. (1997). Antifungal Fractions and Compounds from uncrushed green leaves of Azadirachta indica. Phytoparasitica, 25(1), 33-39.

28. Trish, D.; Banerjee, S.; Yadava, P.K.; Rao, A.R. (2004). Chemopreventive potential of Azadirachta indica (Neem) leaf extract in murine carcinogenesis model systems. Journal of Ethnopharmacology, 92(1), 23-36.

29. Upasana, S.; Anurag, T.; Upadhyay, A.K.; Shukla, U.; Tewari, A. (2002). In vitro antimicrobial study of Neem (Azadirachta indica) seed and leaf extracts. Indian Journal of Veterinary Medicine, 22(2), 109-111.

30. Verma, D.K.; Tripathi, V.J.; Rana, B.K. (1998). Antifungal activity of the seed coat extract of Azadirachta indica. Indian journal of Pharmaceutical Science, 60(5), 305-306. 